\title{
Beyond the prey: male spiders highly invest in silk when producing worthless gifts
}

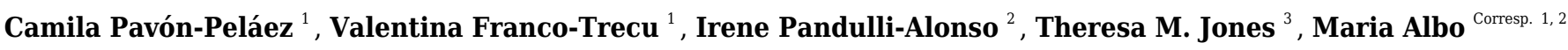 \\ ${ }^{1}$ Departamento de Ecología y Evolución, Facultad de Ciencias, Universidad de la República, Montevideo, montevideo, Uruguay \\ 2 Departamento de Ecología y Biología Evolutiva, Instittuto de investigaciones Biológicas Clemente Estable, Montevideo, montevideo, Uruguay \\ 3 School of BioSciences, The University of Melbourne, Melbourne, Australia \\ Corresponding Author: Maria Albo \\ Email address: malbo@fcien.edu.uy
}

In the spider Paratrechalea ornata, males have two gift-giving mating tactics, offering either a nutritive (prey) or a worthless (prey leftovers) silk wrapped gift to females. Both gift types confer similar mating success and duration and afford males a higher success rate than when they offer no gift. If this lack of difference in the reproductive benefits is true, we would expect all males to offer a gift but some males to offer a worthless gift even if prey are available. To test this, we allowed 18 males to court multiple females over five consecutive trials. In each trial, a male was able to produce a nutritive gift (a live housefly) or a worthless gift (mealworm exuviae). We found that, in line with our predictions, $20 \%$ of the males produced worthless gifts even when they had the opportunity to produce a nutritive one. However, rather than worthless gifts being a cheap tactic, they were related to a higher investment in silk wrapping. This latter result was replicated for worthless gifts produced in both the presence and absence of a live prey item. We propose that variation in gift-giving tactics likely evolved initially as a conditional strategy related to prey availability and male condition in $P$. ornata. Selection may then have favoured silk wrapping as a trait involved in female attraction, leading worthless gift-giving to invade. 
1 Beyond the prey: male spiders highly invest in silk when producing worthless gifts

2

3 Camila Pavón-Peláez ${ }^{1,2}$, Valentina Franco-Trecu ${ }^{2}$, Irene Pandulli-Alonso ${ }^{3}$, Therésa M. Jones ${ }^{4}$

4 and Maria $\mathrm{J} \mathrm{Albo}{ }^{3,5}$

5

6 1Programa de Desarrollo de las Ciencias Básicas (PEDECIBA), Universidad de la República,

7 Uruguay.

8 2Departamento de Ecología y Evolución, Facultad de Ciencias, Universidad de la República,

9 Uruguay

$10{ }^{3}$ Departamento de Ecología y Biología Evolutiva, Instituto de Investigaciones Biológicas

11 Clemente Estable, Uruguay

$12{ }^{4}$ School of BioSciences, The University of Melbourne, 3010 Victoria, Australia

13 5Sección Entomología, Facultad de Ciencias, Universidad de la República, Uruguay

\section{Corresponding author:}

16 Maria J. Albo ${ }^{3,5}$.

17 Iguá 4225, Montevideo, PC: 11400, , Uruguay

18 Email address: mjalbograna@gmail.com

19 


\section{ABSTRACT}

23 In the spider Paratrechalea ornata, males have two gift-giving mating tactics, offering either a

24 nutritive (prey) or a worthless (prey leftovers) silk wrapped gift to females. Both gift types

25 confer similar mating success and duration and afford males a higher success rate than when they

26 offer no gift. If this lack of difference in the reproductive benefits is true, we would expect all

27 males to offer a gift but some males to offer a worthless gift even if prey are available. To test

28 this, we allowed 18 males to court multiple females over five consecutive trials. In each trial, a

29 male was able to produce a nutritive gift (a live housefly) or a worthless gift (mealworm

30 exuviae). We found that, in line with our predictions, $20 \%$ of the males produced worthless gifts

31 even when they had the opportunity to produce a nutritive one. However, rather than worthless

32 gifts being a cheap tactic, they were related to a higher investment in silk wrapping. This latter

result was replicated for worthless gifts produced in both the presence and absence of a live prey

34 item. We propose that variation in gift-giving tactics likely evolved initially as a conditional strategy related to prey availability and male condition in P. ornata. Selection may then have favoured silk wrapping as a trait involved in female attraction, leading worthless gift-giving to

37 invade. 
41

42

43

44

45

46

47

48

\section{Introduction}

In some invertebrate species, individuals (usually males) offer nuptial gifts to potential mates (usually females) increasing their reproductive success (Vahed, 1998; Lewis et al., 2014). The diversity of gifts includes endogenous materials, such as male-produced glandular secretions or proteins in their ejaculates, to exogenously obtained gifts such as nutrient-rich prey or even inedible items (Vahed, 1998; Lewis et al., 2014). Studies of gift-giving species typically demonstrate that males offering gifts gain greater access to matings and have higher paternity compared to males that do not offer a gift, while females may gain nutritive benefits (Vahed, 1998; Lewis et al., 2014). The ability to provide a nuptial gift may be dependent on the condition of the giver thus acting as an honest indicator of some aspect of individual quality (e.g. good hunter, provider) (Dougherty, 2021). In fact, limited (or no) gift production is often associated with a reduction in a male's nutritive status and current physiological condition, ultimately resulting in a decrease of their reproductive success and lifespan (Downes, 1970; Thornhill, 1976; Jia, Jiang \& Sakaluk, 2000; Wedell \& Ritchie, 2004; Engels \& Sauer, 2006; Hall, Bussière \& Brooks, 2009; Albo, Toft \& Bilde, 2011; Albo et al., 2014; Macedo-Rego et al., 2016). A general conclusion from these studies is that the probability of nuptial gift production likely varies with food availability resulting in plastic, environmentally-determined behavioural responses (Pigliucci, 2001; Charmantier et al., 2008; Cornwallis \& Uller, 2010).

Gift-giving plasticity creates a scenario for the origin and maintenance of alternative mating tactics (AMTs), which are discrete individual responses that lead to tactic-specific differential reproductive success (Gross, 1996; Brockmann, 2001; Taborsky, Oliveira \& Brockmann, 2008; Engqvist and Taborsky 2016). The vast majority of AMTs are a conditional strategy in which the expression of the tactics, either dominant or alternative, has a strong 
64 environmental influence. The alternative tactic is less successful than the dominant and therefore,

65 typically occurs at a lower frequency within the population (Gross, 1996; Brockmann, 2001;

66 Taborsky, Oliveira \& Brockmann, 2008; Engqvist and Taborsky 2016). For example, in empidid

67 flies, courting males join together in a swarm each carrying a captured insect prey (nuptial gifts)

68 that function as a stimulus for the females to choose the mate (Kessel, 1955). Empidid males

69 without gifts are usually rejected by females; but males that offer inedible items accrue some

70 mating success albeit less than males offering nutritive prey gifts (Preston-Mafham, 1999). This

71 has been also shown in the gift-giving spider, Pisaura mirabilis. In this species, males provide

72 females either a genuinely nutritive gift (i.e., fresh prey - the dominant tactic) or a worthless gift

73 (i.e., insect exoskeletons - alternative tactic). Worthless gifts are given approximately $30 \%$ of the

74 time and males incur paternity costs as a result of a reduction in mating duration (Albo et al.,

75 2011, 2019). These costs rise because mating duration aligns with the time taken for a female to

76 completely consume the gift contents (approximately 1h, Albo et al., 2011). Male P. mirabilis

77 investment into gift production is dependent on its type: for nutritive gifts (i.e., dominant tactic),

78 male effort is realised through prey capture; for worthless gifts (i.e., alternative tactic) males

79 switch effort towards a higher investment in silk wrapping (Ghislandi et al., 2017). As in the case

80 for empidids, female $P$. mirabilis penalize males that offer worthless gifts indicating that gift

81 content is relatively more important than the silk (Albo et al., 2011).

82 For some species, the act of giving a gift seems to be as important as the content of the

83 gift. For example, in the spider Paratrechalea ornata worthless gifts are frequently (70\% of

84 males) offered to females (Albo et al., 2014), suggesting that this gift type can be a dominant

85 rather than an alternative tactic. For such an evolutionary outcome, several changes would have

86 been necessary to occur. First, it is likely that worthless gifts initially appeared as an alternative 
87 tactic allowing few males to increase their mating chances when prey were limited (Albo et al., 88 2014). Early studies confirm that individual males are plastic and adjust their mating tactic

89

according to prey availability and their own body condition (Albo et al., 2014; Trillo, MeloGonzález \& Albo, 2014). Additionally, when encountering females (especially mated females) in the absence of prey, some males produce a worthless gift, rather than no gift, which substantially increases their mating success (Albo \& Costa, 2010; Albo et al., 2014). Second, for this mating tactic to successfully spread in high numbers in a population, it must have provided males with similar reproductive success as nutritive gifts. A possibility is that, through the silk wrapping males reinforce the gift attraction as an honest signal of their quality, leading females to switch their preferences for the food gift (i.e. the content is not further relevant) or become under exploitation (Arnqvist \& Rowe, 2005; Vahed, 2007). In accordance with this, silk wrapping does play a relevant role in female attraction (Brum, Costa-Schmidt \& De Araújo, 2012; Trillo, MeloGonzález \& Albo, 2014). There is currently no evidence that females discriminate between worthless or nutritive gifts as they are as equally likely to mate (and for comparable durations) with males offering either gift type (Albo et al., 2014; Pandulli-Alonso, Quaglia \& Albo, 2017). Further, mating duration is extremely short in this species giving no time for spider females to complete the gift consumption during sperm transfer (Albo et al., 2014).

Based on the assumption that when a P. ornata male offers a worthless gift he gains similar reproductive benefits to when he offers a nutritive gift, we would expect individuals choosing to offer worthless gifts even when they have the opportunity to produce a nutritive gift. This has never been explicitly tested. Further, if silk wrapping of the gift is reinforcing the signal acting as a reliable quality indicator of the potential mate, we predict that males would invest more in silk wrapping when offering worthless gifts than when the gift is nutritive; and that this 
110 result would hold for worthless gifts produced in the presence or absence of prey. Here, we

111 examined within-individual male mating tactics in $P$. ornata by repeatedly exposing males to

112 sexually mature females in the presence of live prey (nutrient gift) and insect exoskeletons

113 (worthless gift), thus providing males the opportunity to produce either gift type on multiple

114 occasions. We expected that males would be equally likely to produce either gift type. If silk

115 investment is inexpensive compared to the prey capture activity, then males should produce

116 worthless gifts even in the presence of a prey. Such a result would indirectly demonstrate that

117 males have no restrictions on their reproductive benefits in relation to the gift type offered to

118 females. Silk investment in worthless gifts is also predicted to be similar when males are in the

119 presence or absence of prey. Thus, we compared the results from trials with nutrient-rich prey

120 with trials in which we exposed males to females in the absence of prey but with insect

121 exoskeletons. But, as silk wrapping is condition dependent (Trillo, Melo-González \& Albo,

122 2014), a male's decision at any gift giving opportunity may be triggered by their size or body

123 condition, resulting in consistent individual responses. In contrast, if the gift content is more

124 relevant for males in terms of reproductive success (i.e., females exert cryptic female choice that

125 favors nutritive gifts) and/or silk investment is expensive, they should try to capitalize their effort

126 in prey capture to produce nutritive gifts as often as possible.

128 Material and methods

129 Paratrechalea ornata is a semi-aquatic spider found along the edge of streams and rivers from 130 southern Brazil to southern Uruguay. Individuals are crepuscular/nocturnal and can be seen on 131 stones and pebbles emerging from the water (Costa-Schmidt, Carico \& De Araújo, 2008). The

132 typical male courtship behaviour is triggered when detecting female silk (and associated 
133 pheromones) on the substrate (Albo, Costa-Schmidt \& Costa, 2009). At that time, the male

134 vibrates his forelegs and pedipalps while walking along searching for an item. This item may be

135 flying insects emerging from the watercourses (i.e., Ephemeroptera), which are detected mostly

136 through wing vibrations, or an inedible item like prey leftovers or plant parts that the male has

137 eaten or has actively searched among the pebbles, respectively. After securing an item, the male

138 usually wraps it in silk prior to offering it to a female (Albo \& Costa, 2010; Albo et al., 2014).

139 Silk wrapping of the item includes several wrapping bouts, and in each one the male produces a

140 silk sheet in the substrate, deposits the item on it and afterwards covers it with silk (Costa-

141 Schmidt, Carico \& De Araújo, 2008; Albo, Costa-Schmidt \& Costa, 2009). Once the male

142 finishes the silk wrapping he walks (vibrating forelegs) with the gift in his chelicerae searching

143 for a female. When offering the nuptial gift, the male adopts a particular position called the

144 "hyperflexion" in which he presents the nuptial gift to the female (Costa-Schmidt, Carico \& De

145 Araújo, 2008). If a female is receptive, she grabs the gift and the male initiates pedipalp

146 insertions (sperm transfer) while holding the gift with the claws of his third pair of legs. Between

147 each pedipalp insertion the male returns to the face-to-face position and holds the gift again prior 148 to continuing. Once mating and sperm transfer are complete, the pair move apart and the female

149 leaves with the gift (Costa-Schmidt, Carico \& De Araújo, 2008; Albo \& Costa, 2010).

150

151 Spider collection and maintenance

152 We collected juveniles and subadults $(\mathrm{N}=78)$ between 21:00 and 23:00 hours during the 153 reproductive season of 2015 (August-September). Individuals were sampled from a well-studied 154 population from Minas, Uruguay $\left(34^{\circ} 16^{\prime} 40.10^{\prime}\right.$ S, $\left.55^{\circ} 14^{\prime} 00.80^{\prime \prime} \mathrm{W}\right)$, in which the percentage of 155 worthless gifts ranges between 30-80\% in the field (MJ Albo unpublished data). To accelerate 
156 their development, spiders were initially transferred to individual plastic jars $(8 \mathrm{~cm}$ diameter and

$1577 \mathrm{~cm}$ height) and held in a temperature-controlled room at $24.5^{\circ} \mathrm{C}( \pm 0.52 \mathrm{SE}) . \mathrm{We}$ fed

158 individuals with five fruit flies (Drosophila sp.) three times a week and thus, individuals were

159 maintained under similar conditions as in the field, with moderate prey available before the trials.

160 We provided ad libitum water daily through a moistened cotton wool ball. Once individuals

161 reached adulthood, we transferred them to the experimental room (average \pm SE: $20.3 \pm 0.18^{\circ} \mathrm{C}$ ).

162 We continued the same feeding regimen for adult spiders for the duration of the experimental

163 period. To ensure all spiders were sexually mature and the females receptive (Klein, Trillo \& 164 Albo, 2012), unmated adult males and females commenced trials between four and five weeks 165 after their final moult (females: 30 days \pm 2.76 SD; males: 33 days \pm 2.20 SD). Following the 166 completion of all trials, we measured the males size (cephalothorax width) under a 167 stereomicroscope (Jakob, Marshall \& Uetz, 1996).

\section{Experimental design}

Likelihood of mating tactics: nutritive and worthless gifts

171 To examine whether male mating tactics (nutritive/worthless) are equally likely to co-occur, we

172 repeatedly allowed males $(\mathrm{N}=36)$ to court different novel females once every four days over

173 five consecutive trials (Nutritive-Worthless treatment group). We used 42 females that were

174 randomly exposed several times (range 2-8) to different males. This represents the natural

175 environment as females in this species readily mate multiply (Pandulli-Alonso, Quaglia \& Albo,

176 2017). We simulated a typical courting condition observed in the field (MJ Albo personal

177 observations) by exposing males to inedible items along the substrate and a flying prey. Thus, in

178 the Nutritive-Worthless group ( $\mathrm{N}=18$ males), males were provided with a live housefly (Musca 
179

180

181

182

183

184

185

186

187

188

189

190

191

192

193

194

195

196

197

198

199

200

201

domestica) and exuviae of a mealworm (Tenebrio molitor larva), which allowed them to offer either a silk-wrapped nutrient rich gift or a worthless gift.

We performed the trials in transparent glass cages $(30 \times 14 \mathrm{~cm}$ base, $20 \mathrm{~cm}$ height $)$ in which we simulated natural conditions by covering the bottom with pebbles and water. Following previous protocols (Albo et al., 2014; Albo \& Peretti, 2015), we placed a female in the experimental cage $24 \mathrm{~h}$ before introduction of a male, allowing her to habituate and deposit silk that stimulates male courtship and gift production (Albo, Costa-Schmidt \& Costa, 2009). At the start of a trial, a male was placed with the female in the cage along with six mealworm exuviae distributed along the bottom of the cage. To create the scenario where a male could produce either a nutritive or a worthless gift in a single trial, we allowed each male access to both a prey item and an exuviae simultaneously. Once the males started courting females (defined by fast vibrations of forelegs), a live housefly was closely approached to the male via tweezers. This procedure has proved effective for this species as the male can detect the wing vibrations and capture the fly (Albo, Costa-Schmidt \& Costa, 2009; Albo \& Costa, 2010; Brum, Costa-Schmidt \& De Araújo, 2012; Albo et al., 2014; Albo \& Peretti, 2015); additionally allowing us to both control that all males had access to the prey at the same time and meant that the female was not able to capture it herself. All males were presented with a housefly as a first choice to produce a gift. We repeated the action of hand-giving the housefly every $15 \mathrm{~min}$ until the male grabbed and captured the fly, or grabbed an exuviae from the pebbles. We finished the trial when the male wrapped an item in silk and offered it to the female. If the male wrapped an item in silk but did not offer it to the female, we finished the trial an hour after the male ended the silk wrapping (i.e. the last silk wrapping bout). The cases where males grabbed an item but did not wrap it in silk or failed to grab any item were not included for data analyses. In all cases, to ensure spiders 
202 remained unmated throughout their trials, we prevented males from mating using a paintbrush.

203 During each trial, we recorded which gift item (i.e., prey or exuviae) males utilized during 204 courtship.

205

206

Silk investment in worthless and nutritive gifts

207 Using the Nutritive-Worthless group, we measured the duration of silk wrapping, as well as the 208 number of silk wrapping bouts. We calculated total silk wrapping duration (min) as the sum of 209 all wrapping bouts durations. To compare a male's silk investment in the presence and absence 210 of prey, we conducted one further treatment (Worthless group) and examined the results against

211 those from the Nutritive-Worthless group. In the Worthless group, we exposed 18 males to five 212 consecutive females in the absence of a nutrient rich prey but in the presence of exuviae. We 213 obtained data from 64 out of 90 trials in which males produced a worthless gift. Aside from 214 offering a living fly with tweezers, we followed the same experimental protocol described above, 215 so males in both treatment groups had comparable courting opportunities but differed in the type 216 of gift they could produce.

217

218

\section{Data analysis}

219 We used Generalized Linear Mixed Models - GLMM (Pinheiro \& Bates, 2006) in R free 220 software (Core Team, 2019). Among the running models with the same random structure, we 221 assessed each simplification with the Akaike Information Criterion (AIC) using the $\Delta$ AIC $>2$ 222 criterion (Bolker, 2007). All selected models were subject to the customary residual analyses 223 (Pinheiro \& Bates, 2006) and were found to have a satisfactory fit. All initial models included 224 female ID as random effect, but this variable was discarded due to non-significant results. 
226

227 We analysed data of the Nutritive-Worthless group, using a GLMM with binomial distribution

228 (logit link function) to test the probability of producing a worthless gift (wrapped an exuviae in

230 behaviour) as fixed effects. The model included male identity as a random effect and intercept.

231 Considering the repeated measurements of males, we also checked for the repeatability in

232 nuptial gift production (item used), duration of silk wrapping and number of silk-wrapping bouts

233 in the Nutritive-Worthless group in which males can produce the two gift types. We estimated

234 the individual repeatability for all reported response variables using LME with REML

235 implemented with the rptR package (Nakagawa \& Schielzeth, 2010). We included gift type as a

236 fixed effect when analysing variables related to silk investment (duration of silk wrapping and

237 number of silk-wrapping bouts). This analysis describes the relative partitioning of variance into

238 within and between treatment group sources of variance, and the measure obtained (repeatability

239 - R) ranges from 0 (high within-individual variance or low-repeatability) to 1 (low within-

240 individual variance or high-repeatability). The repeatability in behavioural variables was

241 classified into three categories: poorly repeatable $(\mathrm{R}<0.25)$, moderately repeatable $(0.25<\mathrm{R}<$

$2420.50)$ and highly repeatable $(\mathrm{R}>0.50)$. In this method, uncertainty is quantified via parametric

243 bootstrapping (1000 times).

244

245 Silk investment in worthless and nutritive gifts

246 We assessed variation in silk investment using GLMM with Gamma and Poisson distributions

247 (log-link function), by examining duration of silk wrapping (min) and number of silk wrapping

248 bouts, respectively. First, we examined the variation in silk investment in both gift types 
249 (nutritive/worthless) using the Nutritive-Worthless group. This model included gift type, male

250 size and trial number as fixed effect and male identity as random effect. Second, we analysed the

251 silk investment in worthless gifts under the presence or absence of prey by comparing the data

252 from the Nutritive-Worthless and Worthless groups. This model included treatment group, male

253 size and trial number as fixed effects and male identity as random effect.

\section{Results}

Likelihood of mating tactics: nutritive and worthless gifts

257 In trials where males were allowed access to both a prey item and exuviae (Nutritive-Worthless) males produced a nutritive gift in 53 opportunities (mean number of trials per male $\pm \mathrm{SE}=2.94$

$259 \pm 0.39)$ and in 18 trials $(20 \%)$ they produced a worthless gift (mean number of trials per male \pm

$260 \mathrm{SE}=1.00 \pm 0.22$ ). The likelihood of producing a worthless gift was not related either to the male

261 size or the trial number (Table 1).

262

Individual male responses across the five consecutive trials varied (see Figure 1). The

263

264

265

266

267

268

269

270

271

Silk investment in worthless and nutritive gifts 
272 Comparing silk investment between both gift types by using the Nutritive-Worthless group, we

273 found that males invested more time in silk wrapping (Figure 2A) and engaged in more silk

274 wrapping bouts (Figure 2B) (Table 3) when producing worthless compared to nutritive gifts. Silk

275 investment in worthless gifts did not differ between males in the presence (Nutritive-Worthless

276 group) or in the absence of prey (Worthless group) (Table 4).

277 We did not find an effect of either male size or trial number on any of these parameters

278 measured for the Nutritive-Worthless group (Table 3). But when comparing worthless gifts

279 production from both groups, we found that silk wrapping duration was positively related to

280 male size (Figure 3, Table 4).

281

282 Discussion

283 Here, we demonstrated that, even when P. ornata males had the opportunity to produce a

284 nutritive gift, $20 \%$ of them chose to offer worthless gifts. However, the data indicate that males

285 are plastic in their mating tactics: there was a low degree of repeatability and substantial

286 switching between producing nutritive and worthless gifts or vice versa over consecutive trials.

287 Further, we showed that, when producing worthless gifts, males invest more in silk compared to

288 nutritive gifts. This finding agrees with our expectation that males are likely to produce either

289 gift type investing in nutritive content or extra-investment in silk and agrees with early studies

290 showing that they equally secure matings (Albo, Toft \& Bilde, 2014; Pandulli-Alonso, Quaglia

291 \& Albo, 2017). Worthless gifts have probably evolved as a male alternative mating tactic that is

292 condition- and resource-dependent (Albo \& Costa, 2010; Albo et al., 2014; Trillo, Melo-

293 González \& Albo, 2014). Our results suggest that following this, males probably reinforced the

294 silk wrapping of worthless gifts, which in turn may act as a reliable signal of quality for females 
295

296

297

298

299

300

301

302

303

304

305

306

307

308

309

310

311

312

313

314

315

316

317

and allowed worthless gifts to successfully invade the populations (see Albo et al., 2014). Such

an evolutionary scenario would imply paternity share not dependent on the gift content and

hence, equal fitness success for males offering both gift types.

Sensory exploitation of female foraging motivation has been suggested as the origin of nuptial gifts in insects and spiders (Sakaluk, 2000; Bilde et al., 2007; Albo et al., 2017). Females accrue direct nutritional benefits from the gift and at the same time could use the gift as a signal of some aspect of male quality (Zahavi, 1975), such as hunting and provider abilities, which can also include more attractive sons (Fisher, 1930). Environmental limitations, however, seem to have led males to change gift content and produce worthless gifts diminishing the direct benefits for females (MJ Albo unpublished data), but maintaining the honest signal through silk wrapping (Trillo, Melo-González \& Albo, 2014). This is not surprising as plasticity in sexual traits is predicted to be especially common in changing or ephemeral environments (Cornwallis \& Uller, 2010). Riparian spiders, like $P$. ornata, generally feed on aquatic insects whose emergence is unpredictable and largely affected by floods (Lytle, 2002; Iwata, Nakano \& Murakami, 2003;

Sanzone et al., 2003; Knight et al., 2005; Hagen \& Sabo, 2014). Thus, the fluctuating climatic conditions likely favour the evolution and maintenance of flexibility in the nuptial gift production optimizing males reproductive success (Bussière et al., 2008; Kwan et al., 2008; Berger et al., 2014; Miller \& Svensson, 2014; Montiglio et al., 2018).

The trade-off between investing in prey capture or in silk wrapping is therefore a relevant assessment for males living under fluctuating environments. We did not find evidence in relation to the decision of males on gift type production as neither the size nor the courtship history (number of trials) appears to affect it. This result suggests that other factors, such as female attractiveness and/or condition, may play a role modulating the mating tactics (Gaskett, 2007). In 
318 fact, a recent study has found that $P$. ornata males can add more flies to the gift when females

319 are in good body condition (Solano-Brenes et al., 2021). Though in our case all individuals were

320 equally fed, we cannot rule out potential effects associated with variation in a female's condition.

321 Nevertheless, our results regarding silk investment for worthless gifts give valuable information

322 on this issue. We found that males spent more time and deposited more silk during worthless gift

323 production than when the gift was nutritive, and that large males enhance the silk wrapping of

324 the item as they are able to add more silk to the gift. Additional silk would be especially

325 important when the gift is worthless, as can better camouflage its content and still attract females

326 (visually and chemically) (Brum, Costa-Schmidt \& De Araújo, 2012; Trillo, Melo-González \&

327 Albo, 2014). Silk may replace the edible content if it is nutritionally important but it is unknown

328 whether females feed from the silk wrapping of the gift. On the other hand, when females receive

329 worthless gifts they may try to leave the mating before the sperm transfer is completed. Hence,

330 by adding more silk, males may acquire benefits in terms of controlling the mating duration by

331 holding the gift with the claws of their third pair of legs during the sperm transfer thus reducing

332 the likelihood the female will steal it, as is described for the closely related gift-giving spider $P$.

333 mirabilis (Andersen et al., 2008; Ghislandi et al., 2017).

334 Overall, research indicates that silk wrapping is a relevant male trait in gift-giving

335 spiders, especially when a male produces a worthless gift, but the cost of this strategy is

336 unknown. Ghislandi et al. (2017) described worthless gifts as a cheap tactic (Albo et al., 2011;

337 but see Albo, Toft \& Bilde, 2011) in which males invest more silk to disguise the content, but are

338 still able to increase their own body mass (despite this extra-silk investment) by eating the prey

339 themselves. We doubt this is the same for P. ornata because, in the field, worthless gifts may be

340 prey leftovers but very often include inedible items (like plant parts) (Albo et al., 2014). This 
341 means that males cannot feed from such non-prey items and thus they do not gain energy but

342 rather probably spend energetic resources as further invest more in the silk wrapping. Taken

343 together these lines of evidence suggest that a male's silk investment is potentially an honest

344 signal that females can use to measure male quality (Albo, Toft \& Bilde, 2011; Trillo, Melo-

345 González \& Albo, 2014; Macedo-Rego et al., 2016).

346 This is a win-win scenario for males, but from the females' perspective, the worthless gift

347 tactic may reduce their fitness success. Commonly, polyandry in gift-giving species is

348 maintained throughout the food benefits gained by females from the gift during each mating

349 (Arnqvist \& Nilsson, 2000). We know that $P$. ornata females suffer from a reduction in

350 fecundity if they accept multiple worthless rather than nutritive gifts (Pandulli-Alonso, Quaglia

351 \& Albo, 2017). Two scenarios are possible: either females are under exploitation suffering

352 fitness costs and sexual conflict occurs (Arnqvist \& Rowe, 2005) or their preferences for the gift

353 content have co-evolved with male wrapping behaviours as, under natural conditions, they can

354 supply food demands by increasing the foraging activity and thus their choice is likely cost

355 neutral. It has been proposed that, in species with a high proportion of deceptive worthless gifts,

356 female receptivity based on hunger state is unlikely (Pandulli-Alonso, Quaglia \& Albo, 2017).

357 There is no unequivocal study to resolve this puzzle. Some evidence suggests females may

358 cryptically bias paternity towards males offering nutritive gifts (Albo \& Peretti, 2015). Given

359 this, offering a nutritive gift would provide fertilization benefits to males over offering a

360 worthless gift and thus, selection would favour this tactic. This can explain the maintenance of

361 nutritive gifts but not the high proportion of worthless gifts. Recent field studies have revealed

362 that worthless gifts proportion not only vary among populations (38-96\%) with different

363 environmental conditions, but also within the mating season in a single population (MJ Albo 
364 unpublished data). This is the case of our study population in which males offering worthless

365 gifts occur between $30-80 \%$ along the season. This variation in the mating tactic lead us to the

366 discussion on whether offering nutritive gifts under certain dates might reward higher

367 reproductive success for males than offering worthless gifts. How both gift-giving tactics are 368 actually maintained is an open question.

\section{Conclusions}

371

372

373

374

375

376

377

378

379

380

381

382

383

384

385

386

In summary, here we demonstrate that males are plastic in terms of whether they present a nutritive or a worthless gift. We suggest therefore that the gift-giving mating tactics were initially likely produced from a conditional strategy (Gross, 1996) related to prey availability and male condition. This phenotypic plasticity is revealed not only in the decision of using a prey or an inedible item and produce either a nutritive or a worthless nuptial gift, but also in the amount of silk deposited. This suggests that over evolutionary time the silk wrapping potentially become further relevant for female attraction, leading worthless gifts to invade the populations. The fact that the nuptial gift is composed by an exogenous (prey) and an endogenous (silk) part allows males to differentially allocate their energy and resources. There is a trade-off between investing in the exogenous part or in the endogenous one probably associated with fitness outcomes, which is relevant to understand whether the presentation of worthless and nutritive gifts result in similar fitness success in P. ornata.

84 Acknowledgments

We thank Federico Reyes and Silvina Cortes for their help in the field and laboratory work. Laura Montes de Oca for her help in spiders' maintenance. We thank Sebastián Horta and 
387 Sistema Nacional de Areas Protegidas (SNAP) for the support to carry out this research in

388 protected areas of Uruguay; Marina Castro INIA -La Estanzuela, Uruguay for housefly breeding 389 material. We are grateful to Mauro Martínez, Bruno Buzatto, Laura Quintana and Daniel Naya 390 for fruitful comments on the first draft.

391

\section{References}

393

394

395

396

397

398

399

400

401

402

403

404

405

406

407

408

409

Albo MJ, Costa-Schmidt LE, Costa FG. 2009. To feed or to wrap? Female silk cues elicit male nuptial gift construction in a semiaquatic trechaleid spider. Journal of Zoology 277:284290. DOI: 10.1111/j.1469-7998.2008.00539.x.

Albo MJ, Costa FG. 2010. Nuptial gift-giving behaviour and male mating effort in the Neotropical spider Paratrechalea ornata (Trechaleidae). Animal Behaviour 79:1031-1036. DOI: 10.1016/j.anbehav.2010.01.018.

Albo MJ, Franco-Trecu V, Wojciechowski FJ, Toft S, Bilde T. 2019. Maintenance of deceptive gifts in a natural spider population: ecological and demographic factors. Behavioral Ecology 30:1-8. DOI: 10.1093/beheco/arz040 The.

Albo MJ, Macías-Hernández N, Bilde T, Toft S. 2017. Mutual benefit from exploitation of female foraging motivation may account for the early evolution of gifts in spiders. Animal Behaviour 129. DOI: 10.1016/j.anbehav.2017.05.001.

Albo MJ, Melo-González V, Carballo M, Baldenegro F, Trillo MC, Costa FG. 2014. Evolution of worthless gifts is favoured by male condition and prey access in spiders. Animal Behaviour 92:25-31. DOI: 10.1016/j.anbehav.2014.03.018.

Albo MJ, Peretti A V. 2015. Worthless and nutritive nuptial gifts: mating duration, sperm stored and potential female decisions in spiders. PLOS ONE 10:1-15. DOI: 
10.1371/journal.pone.0129453.

411

412

413

414

415

416

417

418

419

420

421

422

423

424

425

426

427

428

429

430

431

432

Albo MJ, Toft S, Bilde T. 2011. Condition dependence of male nuptial gift construction in the spider Pisaura mirabilis (Pisauridae). Journal of Ethology 29:473-479. DOI: 10.1007/s10164-011-0281-1.

Albo MJ, Toft S, Bilde T. 2014. Sexual selection, ecology, and evolution of nuptial gifts in spiders. In: Sexual Selection: Perspectives and Models from the Neotropics. Elsevier, 183200.

Albo MJ, Winther G, Tuni C, Toft S, Bilde T. 2011. Worthless donations: male deception and female counter play in a nuptial gift-giving spider. BMC Evolutionary Biology 11:329. DOI: 10.1186/1471-2148-11-329.

Andersen T, Bollerup K, Toft S, Bilde T. 2008. Why do males of the spider Pisaura mirabilis wrap their nuptial gifts in silk: Female preference or male control? Ethology 114:775-781. DOI: $10.1111 / \mathrm{j} .1439-0310.2008 .01529 . x$.

Arnqvist G, Nilsson T. 2000. The evolution of polyandry: multiple mating and female fitness in insects. Animal Behaviour 60:145-164. DOI: 10.1006/anbe.2000.1446.

Arnqvist G, Rowe L. 2005. Sexual conflict. Princeton University Press.

Berger D, Grieshop K, Lind MI, Goenaga J, Maklakov AA, Arnqvist G. 2014. Intralocus sexual conflict and environmental stress. Evolution 68:2184-2196. DOI: 10.1111/evo.12439.

Bilde T, Tuni C, Elsayed R, Pekar S, Toft S. 2007. Nuptial gifts of male spiders: sensory exploitation of the female's maternal care instinct or foraging motivation? Animal Behaviour 73:267-273. DOI: 10.1016/j.anbehav.2006.05.014.

Bolker B. 2007. Ecological Models and Data in R.

Brockmann HJ. 2001. The evolution of alternative strategies and tactics. Advances in the Study 
of Behavior 30:1-51. DOI: 10.1016/S0065-3454(01)80004-8.

434 Brum PED, Costa-Schmidt LE, De Araújo AM. 2012. It is a matter of taste: Chemical signals mediate nuptial gift acceptance in a neotropical spider. Behavioral Ecology. DOI:

437

438

439

440

441

442

443

444

445

446

447

448

449

450

451

452

453

454

455

Bussière LF, Hunt J, Stölting KN, Jennions MD, Brooks R. 2008. Mate choice for genetic quality when environments vary: Suggestions for empirical progress. Genetica 134:69-78. DOI: $10.1007 / \mathrm{s} 10709-007-9220-\mathrm{z}$.

Charmantier A, McCleery RH, Cole LR, Perrins C, Kruuk LEB, Sheldon BC. 2008. Adaptive phenotypic plasticity in response to climate change in a wild bird population. Science 320:800-803. DOI: 10.1126/science.1157174.

Core Team R. 2019. R: A language and environment for statistical computing.

Cornwallis CK, Uller T. 2010. Towards an evolutionary ecology of sexual traits. Trends in Ecology and Evolution 25:145-152. DOI: 10.1016/j.tree.2009.09.008.

Costa-Schmidt LE, Carico JE, De Araújo AM. 2008. Nuptial gifts and sexual behavior in two species of spider (Araneae, Trechaleidae, Paratrechalea). Naturwissenschaften 95:731-739. DOI: $10.1007 / \mathrm{s} 00114-008-0379-7$.

Engqvist, L., and M. Taborsky. 2016. The evolution of genetic and conditional alternative reproductive tactics. Proceedings of the Royal Society B 283:20152945. DOI: $10.1098 /$ rspb.2015.2945

Dougherty LR. 2021. Meta-analysis reveals that animal sexual signalling behaviour is honest and resource based. Nature Ecology and Evolution 5:688-699. DOI: 10.1038/s41559-02101409-z.

Downes JA. 1970. The feeding and mating behaviour of the specialized Empidinae (Diptera); 
456

457

458

459

460

461

462

463

464

465

466

467

468

469

470

471

472

473

474

475

476

477

478

observations on four species of Rhamphomyza in the high arctic and a general discussion. The Canadian Entomologist 102:760-791. DOI: 10.4039/Ent102769-7.

Engels S, Sauer KP. 2006. Resource-dependent nuptial feeding in Panorpa vulgaris: An honest signal for male quality. Behavioral Ecology 17:628-632. DOI: 10.1093/beheco/ark007.

Fisher RA. 1930. The genetical theory of natural selection. Oxford, UK: Oxford University Press.

Gaskett AC. 2007. Spider sex pheromones: emission, reception, structures, and functions. Biological Reviews 82:27-48. DOI: 10.1111/j.1469-185X.2006.00002.x.

Ghislandi PG, Beyer M, Velado P, Tuni C. 2017. Silk wrapping of nuptial gifts aids cheating behaviour in male spiders. Behavioral Ecology 00:1-6. DOI: 10.1093/beheco/arx028.

Gross MR. 1996. Alternative reproductive strategies and tactics: diversity within sexes. Trends in Ecology \& Evolution 11:92-98. DOI: 10.1016/0169-5347(96)81050-0.

Hagen EM, Sabo JL. 2014. Temporal variability in insectivorous bat activity along two desert streams with contrasting patterns of prey availability. Journal of Arid Environments 102:104-112. DOI: 10.1016/j.jaridenv.2013.11.016.

Hall MD, Bussière LF, Brooks R. 2009. Diet-dependent female evolution influences male lifespan in a nuptial feeding insect. Journal of Evolutionary Biology 22:873-881. DOI: 10.1111/j.1420-9101.2009.01687.x.

Iwata T, Nakano S, Murakami M. 2003. Stream meanders increase insectivorous bird abundance in riparian deciduous forests. Ecography 26:325-337. DOI: 10.1034/j.16000587.2003.03355.x.

Jakob EM, Marshall SD, Uetz GW. 1996. Estimating fitness: a comparison of body condition indices. Oikos 77:61-67. DOI: 10.2307/3546755. 
479 Jia Z, Jiang Z, Sakaluk SK. 2000. Nutritional condition influences investment by male katydids 480 in nuptial food gifts. Ecological Entomology 25:115-118. DOI: 10.1046/j.1365-

481 2311.2000.00239.x.

482 Kessel EL. 1955. The mating activities of balloon flies. Systematic Zoology 4:97-104. DOI:

483

484

485

486

487

488

489

490

491

492

493

494

495

496

497

498

499

500

501 $10.2307 / 2411862$.

Klein AL, Trillo MC, Albo MJ. 2012. Sexual receptivity varies according to female age in a Neotropical nuptial gift-giving spider. Journal of Arachnology 40:138-140. DOI: 10.1636/H11-31.1.

Knight TM, McCoy MW, Chase JM, McCoy KA, Holt RD. 2005. Trophic cascades across ecosystems. Nature 437:880-3. DOI: 10.1038/nature03962.

Kwan L, Bedhomme S, Prasad NG, Chippindale AK. 2008. Sexual conflict and environmental change: trade-offs within and between the sexes during the evolution of desiccation resistance. Journal of Genetics 87:383-394. DOI: 10.1007/s12041-008-0061-z.

Lewis SM, Vahed K, Koene JM, Engqvist L, Bussière LF, Perry JC, Gwynne D, Lehmann GUC. 2014. Emerging issues in the evolution of animal nuptial gifts. Biology letters 10:20140336. DOI: $10.1098 / \mathrm{rsbl} .2014 .0336$.

Lytle DA. 2002. Flash floods and aquatic insect life-history evolution: evaluation of multiple models. Ecology 83:370-385. DOI: 10.1890/0012-9658(2002)083[0370:FFAAIL]2.0.CO;2.

Macedo-Rego RC, Costa-Schmidt LE, Santos ESA, Machado G. 2016. Negative effects of prolonged dietary restriction on male mating effort: Nuptial gifts as honest indicators of long-term male condition. Scientific Reports 6:1-8. DOI: 10.1038/srep21846.

Miller CW, Svensson EI. 2014. Sexual selection in complex environments. Annual Review of Entomology 59:427-445. DOI: 10.1146/annurev-ento-011613-162044. 
502 Montiglio PO, Dammhahn M, Dubuc Messier G, Réale D. 2018. The pace-of-life syndrome

503 revisited: the role of ecological conditions and natural history on the slow-fast continuum.

504 Behavioral Ecology and Sociobiology 72:116. DOI: 10.1007/s00265-018-2526-2.

505 Nakagawa S, Schielzeth H. 2010. Repeatability for Gaussian and non-Gaussian data: A practical 506 guide for biologists. Biological Reviews 85:935-956. DOI: 10.1111/j.1469-

$507 \quad$ 185X.2010.00141.x.

508 Pandulli-Alonso I, Quaglia A, Albo MJ. 2017. Females of a gift-giving spider do not trade sex 509 for food gifts: A consequence of male deception? BMC Evolutionary Biology 17:1-8. DOI: $510 \quad 10.1186 / \mathrm{s} 12862-017-0953-8$.

511 Pigliucci M. 2001. Phenotypic plasticity. In: Fox CW, Roff DA, Fairbairn DJ eds. Evolutionary 512 Ecology. Concepts and case studies. Oxford University Press, 58-69.

513 Pinheiro J, Bates D. 2006. Mixed-Effects Models in S and S-PLUS. Springer Science \& Business $514 \quad$ Media, editor.

515 Preston-Mafham KG. 1999. Courtship and mating in Empis (Xanthempis) trigramma Meig., E.

516 tesselata F., and E. (Polyblepharis) opaca F. (Diptera: Empididae) and the possible 517 implication of "cheating" behavior. Journal of Zoology 247:239-246. DOI:

$518 \quad 10.1017 / \mathrm{S} 0952836999002113$.

519 Sakaluk SK. 2000. Sensory exploitation as an evolutionary origin to nuptial food gifts in insects. $520 \quad$ Proc. R. Soc. B 267:339-343. DOI: $10.1098 /$ rspb.2000.1006.

521 Sanzone DM, Meyer JL, Marti E, Gardiner EP, Tank JL, Grimm NB. 2003. Carbon and nitrogen 522 transfer from a desert stream to riparian predators. Oecologia 134:238-250. DOI:

523 10.1007/s00442-002-1113-3.

524 Solano-Brenes D, Costa-Schmidt LE, Albo MJ, Machado G. 2021. Differential allocation in a 
525 gift-giving spider: males adjust their reproductive investment in response to female

526 condition. BMC Ecology and Evolution 21:140. DOI: 10.1186/s12862-021-01870-1.

527 Taborsky M, Oliveira RF, Brockmann HJ. 2008. The evolution of alternative reproductive

528 tactics: Concepts and questions. In: Alternative Reproductive Tactics. Cambridge University

529 Press, 1-21.

530 Thornhill R. 1976. Sexual selection and nuptial feeding behavior in Bittacus apicalis (Insecta:

531 Mecoptera). The American Naturalist 110:529-548. DOI: 10.1086/283089.

532 Trillo MC, Melo-González V, Albo MJ. 2014. Silk wrapping of nuptial gifts as visual signal for

533 female attraction in a crepuscular spider. Naturwissenschaften 101:123-130. DOI:

$534 \quad 10.1007 / \mathrm{s} 00114-013-1139-\mathrm{x}$.

535 Vahed K. 1998. The function of nuptial feeding in insects: a review of empirical studies.

536 Biological Reviews 73:43-78. DOI: 10.1017/S0006323197005112.

537 Vahed K. 2007. All that glisters is not gold: Sensory bias, sexual conflict and nuptial feeding in 538 insects and spiders. Ethology 113:105-127. DOI: 10.1111/j.1439-0310.2006.01312.x.

539 Wedell N, Ritchie MG. 2004. Male age, mating status and nuptial gift quality in a bushcricket.

540 Animal Behaviour 67:1059-1065. DOI: 10.1016/j.anbehav.2003.10.007.

541 Zahavi A. 1975. Mate selection-A selection for a handicap. Journal of Theoretical Biology

542 53:205-214. DOI: 10.1016/0022-5193(75)90111-3. 


\section{Figure 1}

Individuals choice for producing nutritive or worthless gifts

Proportions of gift type produced by each individual male of Paratrechalea ornata. For each individual, the proportions of nutritive gifts are shown in white and worthless gifts in grey. These data are from the Nutritive-Worthless group $(n=18)$ in which males had the opportunity of producing a nutritive or a worthless gift. The bars show that $39 \%$ of the males always produced a nutritive gift, $11 \%$ always produced a worthless gift and $50 \%$ of the males showed a variable response. 


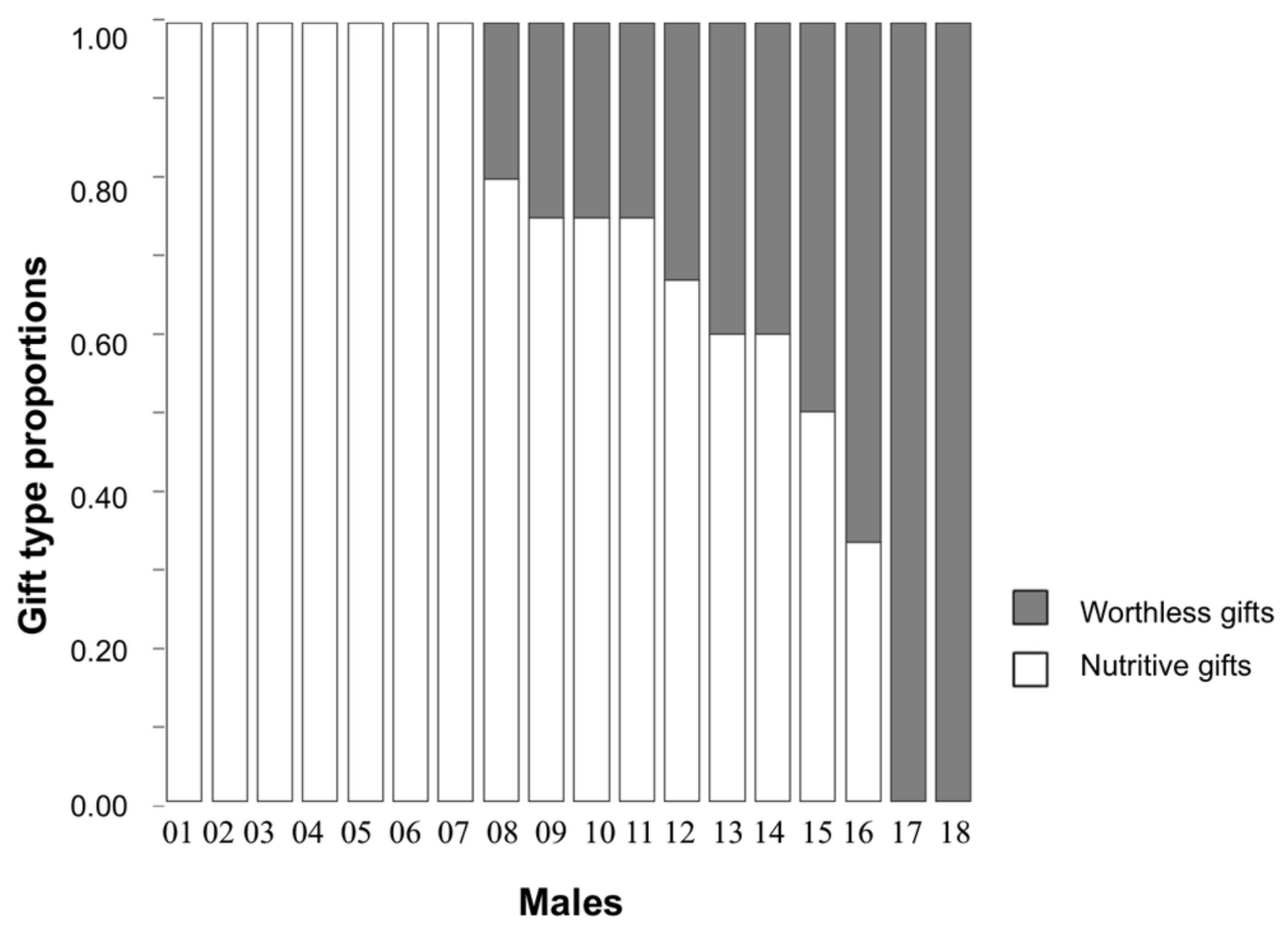




\section{Figure 2}

Males silk investment in nuptial gifts

Differences in silk investment by Paratrechalea ornata males in relation to the experimental groups (Nutritive-Worthless/Worthless) and the gift type (Nutritive/Worthless gift). A)

Differences in silk wrapping duration ( $\mathrm{min}$ ) and B) differences in number of silk wrapping bouts. Data of nutritive gifts are shown as white points and worthless gifts as grey points. First and third quartile are represented with boxes, the median is shown as thick horizontal line and the outliers as black points. Males from the Nutritive-Worthless group $(n=18)$ had the opportunity to produce nutritive or worthless gifts, and males from the Worthless group $(n=18)$ had the opportunity to produce only worthless gifts. Different letters indicate significant differences $(p<0.05)$. 


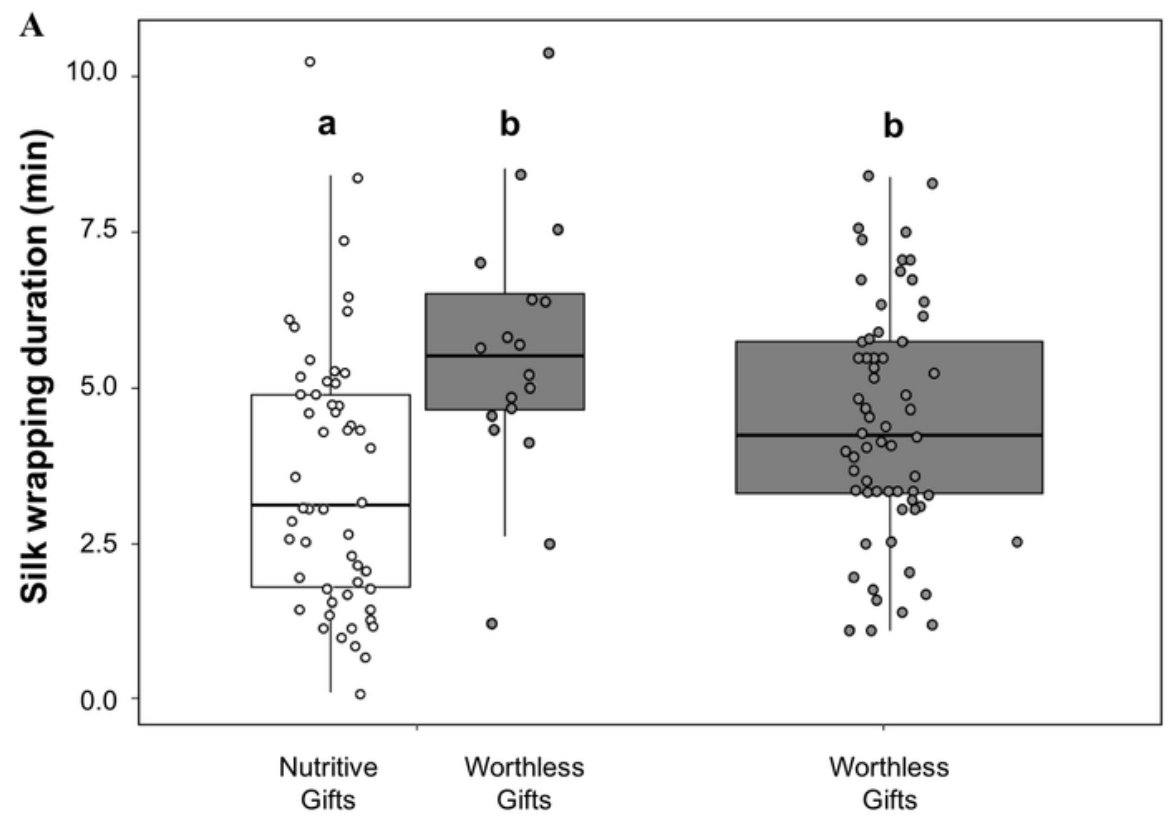

Nutritive-Worthless Worthless

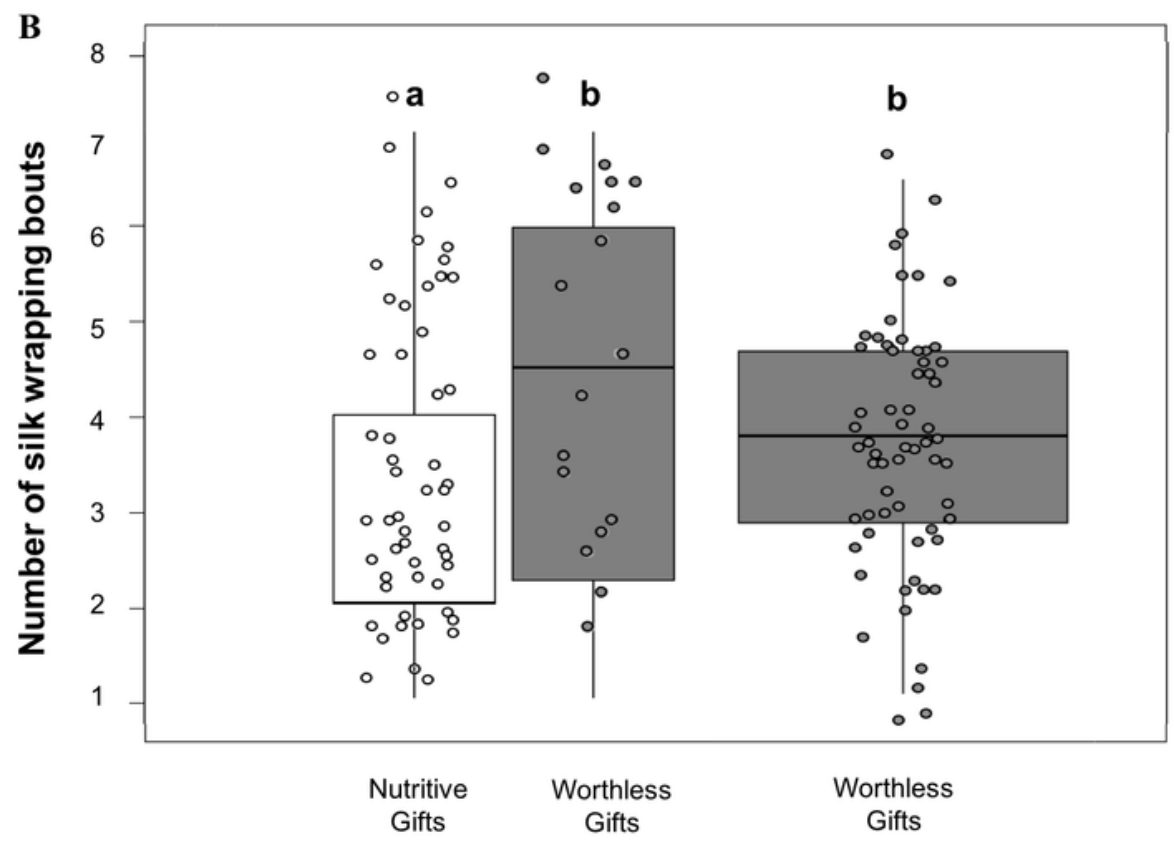

Nutritive-Worthless Group 
Figure 3

Silk investment in relation to male size

Variation of silk wrapping duration according to male size for worthless gift production in Paratrechalea ornata. Data are shown as black points, linear predictor in black and the confidence interval in grey. These data are from males used in the two different experimental groups. Males from the Nutritive-Worthless group $(n=18)$ had the opportunity to produce nutritive or worthless gifts, and males from the Worthless group $(n=18)$ had the opportunity to produce only worthless gifts. Different letters indicate significant differences $(p<0.05)$.

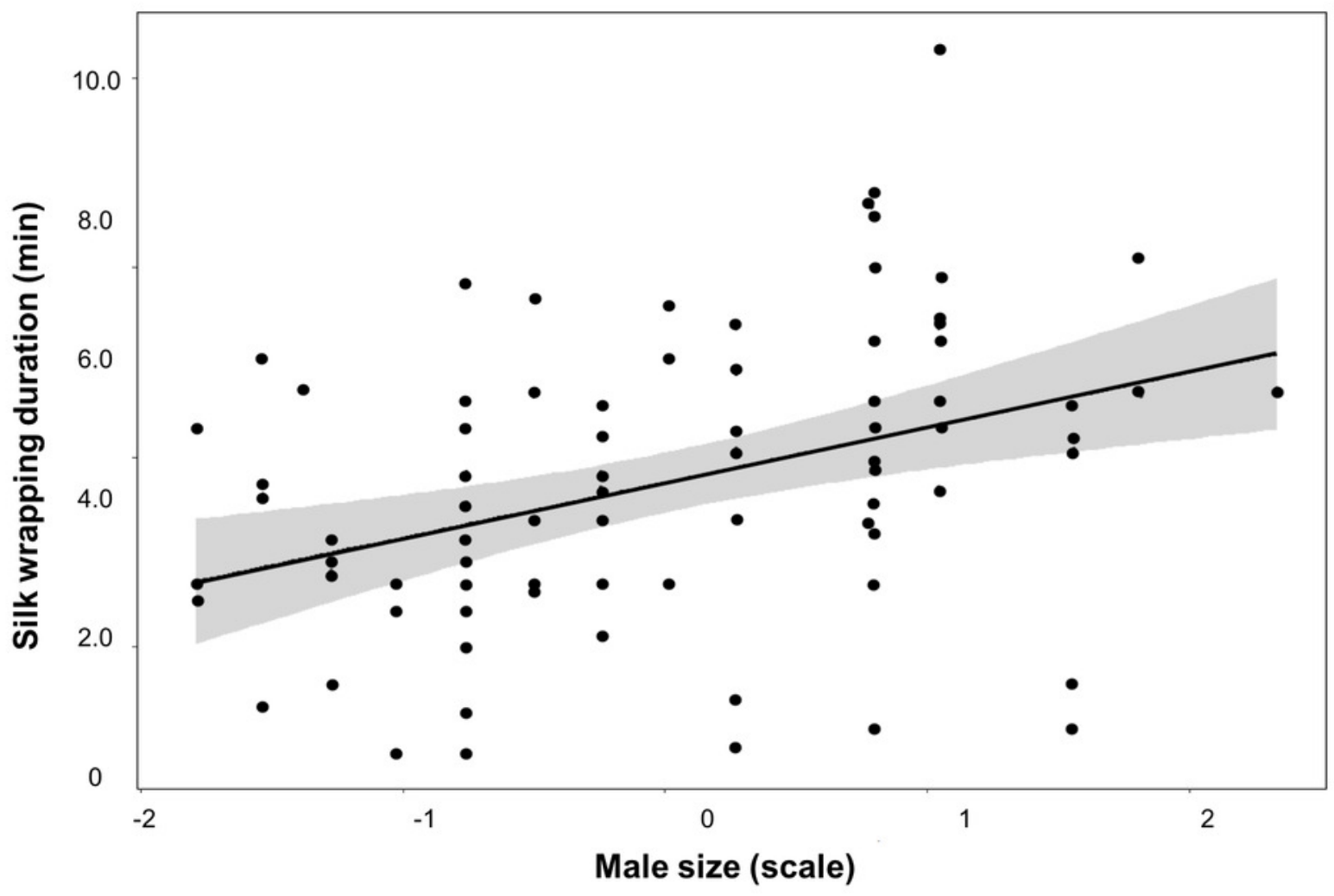




\section{Table $\mathbf{1}$ (on next page)}

Likelihood of producing a worthless gift.

Parameter estimates (SE) and p-values using Generalized Linear Mixed Models with a Binomial distribution (logit link function) to test the probability of producing a worthless gift (wrapped an exuviae in silk) according to the male size and the trial number in the NutritiveWorthless group. The completed model is shown due to no significant effect was found. The model includes male identity (MaleID) as random effect (included as intercept). 
1 Table 1.

2

\begin{tabular}{lccc}
\hline & \multicolumn{3}{c}{ Fixed effects } \\
\hline & Intercept & Male size & $\begin{array}{c}\text { Number of } \\
\text { experiment Trial } \\
\text { number }\end{array}$ \\
\hline $\begin{array}{c}\text { Worthless gift } \\
\text { production }\end{array}$ & $\underline{(6.37)}$ & $\underline{(1.45)}$ & Estimate $=-0.10$ \\
& $\mathrm{p}=0.11$ & $\mathrm{p}=0.15$ & $\underline{(0.22)}$
\end{tabular}

\section{Random effects (Male ID)}

Worthless gift $\quad$ Variance $=1.19$

production $\quad \mathrm{SD}=1.09$ 


\section{Table 2 (on next page)}

Individual behavioural repeatability

Estimates of individual repeatability for the variables measured in the Nutritive-Worthless group. Repeatability $(R)$ ranges from 0 (high within-individual variance or low-repeatability) to 1 (low within-individual variance or high-repeatability). The confidence interval $(\mathrm{Cl})$ was estimated at $95 \%$. 
1 Table 2.

2

3

\section{Nutritive-Worthless}

4

group

\begin{tabular}{lccc}
\hline & R & CI & p \\
Gift type production & 0.14 & $0-0.33$ & 0.08 \\
Silk wrapping duration & 0.05 & $0-0.18$ & 0.24 \\
Number of silk wrapping bouts & 0.08 & $0-0.21$ & 0.16 \\
\hline
\end{tabular}




\section{Table 3 (on next page)}

Silk investment in nutritive and worthless gifts

Parameter estimates and p-values (with significance shown in bold) using Generalized Linear Mixed Models with a Gamma or Poisson distribution and a log link function to explain differences in the duration of silk wrapping and number of silk wrapping bouts according to the gift type (nutritive/worthless) used by males in the Nutritive-Worthless group. The initial model included also male size, trial number and the gift type*male size interaction. Model selection was performed by the Akaike Information Criterion (AIC). 


\section{Table 3.}

\begin{tabular}{|c|c|c|c|c|c|c|c|}
\hline \multicolumn{2}{|c|}{ Silk wrapping duration } & \multirow{2}{*}{$\begin{array}{l}\text { Intercept } \\
2.26(1.46)\end{array}$} & \multirow{2}{*}{$\begin{array}{c}\begin{array}{c}\text { Gift type } \\
\text { (Worthless Gift) }\end{array} \\
-2.51(2.44)\end{array}$} & \multirow{2}{*}{$\begin{array}{c}\text { Male size } \\
-0.24(0.34)\end{array}$} & \multirow{2}{*}{$\begin{array}{c}\begin{array}{c}\text { ExperimentTr } \\
\text { ial number }\end{array} \\
-0.002(0.05)\end{array}$} & \multirow{2}{*}{$\begin{array}{l}\begin{array}{l}\text { Gift type: } \\
\text { Male size }\end{array} \\
0.68(0.56)\end{array}$} & $\Delta \mathbf{A I C}$ \\
\hline Model 1 & Estimate (SE) & & & & & & 3205 \\
\hline & $\mathrm{p}$ & 0.12 & 0.30 & 0.48 & 0.97 & 0.22 & ב \\
\hline \multirow[t]{2}{*}{ Model 2} & Estimate (SE) & $1.50(1.32)$ & $0.48(0.18)$ & $-0.06(0.31)$ & $0.006(0.05)$ & - & 3194 \\
\hline & $\mathrm{p}$ & 0.26 & 0.007 & 0.83 & 0.90 & - & \\
\hline \multirow[t]{2}{*}{ Model 3} & Estimate (SE) & $1.51(1.32)$ & $0.48(0.18)$ & $-0.06(0.31)$ & - & - & $317 \underline{2}$ \\
\hline & $\mathrm{p}$ & 0.25 & 0.007 & 0.84 & - & - & \\
\hline \multirow[t]{2}{*}{ Model 4} & Estimate (SE) & $1.24(0.10)$ & $0.47(0.17)$ & - & - & - & $315 \underline{0}$ \\
\hline & $\mathrm{p}$ & $<0.0001$ & 0.006 & - & - & - & \\
\hline \multicolumn{2}{|c|}{$\begin{array}{l}\text { Number of silk wrapping } \\
\text { bouts }\end{array}$} & Intercept & $\begin{array}{c}\text { Gift type } \\
\text { (Worthless Gift) }\end{array}$ & Male size & $\begin{array}{l}\text { ExperimentTr } \\
\text { ial number }\end{array}$ & $\begin{array}{l}\text { Gift type: } \\
\text { Male size }\end{array}$ & $\Delta \mathbf{A I C}$ \\
\hline \multirow[t]{2}{*}{ Model 1} & Estimate (SE) & $1.02(0.17)$ & $0.28(0.16)$ & $-0.04(0.09)$ & $0.02(0.05)$ & $0.16(0.15)$ & 2825 \\
\hline & $\mathrm{p}$ & $<0.0001$ & 0.08 & 0.72 & 0.70 & 0.30 & \\
\hline \multirow[t]{2}{*}{ Model 2} & Estimate (SE) & $1.01(0.17)$ & $0.31(0.16)$ & $0.02(0.08)$ & $0.02(0.05)$ & - & 2814 \\
\hline & $\mathrm{p}$ & $<0.0001$ & 0.04 & 0.82 & 0.61 & - & $28+\underline{4}$ \\
\hline \multirow[t]{2}{*}{ Model 3} & Estimate (SE) & $1.01(0.17)$ & $0.33(0.15)$ & - & $0.02(0.05)$ & - & $279 \underline{2}$ \\
\hline & $\mathrm{p}$ & $<0.0001$ & 0.03 & - & 0.60 & - & \\
\hline \multirow[t]{2}{*}{ Model 4} & Estimate (SE) & $1.08(0.09)$ & $0.33(0.15)$ & - & - & - & $277 \underline{0}$ \\
\hline & $\mathrm{p}$ & $<0.0001$ & 0.03 & - & - & & \\
\hline
\end{tabular}




\section{Table 4 (on next page)}

Silk investment in worthless gifts when prey is present or absent.

Parameter estimates and p-values (with significance shown in bold) using Generalized Linear Mixed Models with a Gamma and Poisson distribution and a log link function to assess differences in the duration of silk wrapping and number of silk wrapping bouts for the worthless gifts produced by males in the Nutritive-Worthless group and the Worthless group. The initial model included also male size, trial number and the group*male size interaction. Model selection was performed by the Akaike Information Criterion (AIC). 


\section{Table 4.}

2

3 Silk $\mid$ wrapping duration $\quad$ Intercept $\quad \begin{gathered}\text { Group (Nutritive- } \\ \text { Worthless) }\end{gathered} \quad$ Male size

ExperimentT rial number
Group: $\quad \triangle \mathrm{AIC}$ Male size

\begin{tabular}{|c|c|c|c|c|c|c|c|}
\hline Model 1 & $\begin{array}{c}\text { Estimate (SE) } \\
p\end{array}$ & $\begin{array}{c}1.38(0.13) \\
<\mathbf{0 . 0 0 0 1}\end{array}$ & $\begin{array}{c}0.13(0.19) \\
0.48\end{array}$ & $\begin{array}{c}0.15(0.09) \\
0.08\end{array}$ & $\begin{array}{c}0.03(0.03) \\
0.42\end{array}$ & $\begin{array}{c}-0.04(0.17) \\
0.82\end{array}$ & $340 \underline{5}$ \\
\hline Model 2 & $\begin{array}{c}\text { Estimate (SE) } \\
\mathrm{p}\end{array}$ & $\begin{array}{c}1.39(0.13) \\
<\mathbf{0 . 0 0 0 1}\end{array}$ & $\begin{array}{c}0.11(0.17) \\
0.50\end{array}$ & $\begin{array}{c}0.14(0.07) \\
0.06\end{array}$ & $\begin{array}{c}0.02(0.03) \\
0.43\end{array}$ & $\begin{array}{l}- \\
-\end{array}$ & $338 \underline{4}$ \\
\hline Model 3 & $\begin{array}{c}\text { Estimate (SE) } \\
\mathrm{p}\end{array}$ & $\begin{array}{c}1.46(0.08) \\
<\mathbf{0 . 0 0 0 1}\end{array}$ & $\begin{array}{c}0.11(0.17) \\
0.51\end{array}$ & $\begin{array}{c}0.14(0.07) \\
0.06\end{array}$ & - & - & $336 \underline{2}$ \\
\hline Model 4 & $\begin{array}{c}\text { Estimate (SE) } \\
\mathrm{p}\end{array}$ & $\begin{array}{c}-0.24(0.71) \\
0.73 \\
\end{array}$ & $\begin{array}{l}- \\
-\end{array}$ & $\begin{array}{c}0.42(0.17) \\
\mathbf{0 . 0 1}\end{array}$ & - & $\begin{array}{l}- \\
-\end{array}$ & $335 \underline{0}$ \\
\hline $\begin{array}{l}\text { Number } \\
\text { wrapping }\end{array}$ & $\begin{array}{l}\text { silk } \\
\text { bouts }\end{array}$ & Intercept & $\begin{array}{l}\text { Group (Nutritive- } \\
\text { Worthless) }\end{array}$ & Male size & $\begin{array}{l}\text { ExperimentT } \\
\text { rial number }\end{array}$ & $\begin{array}{l}\text { Group: } \\
\text { Male size }\end{array}$ & $\Delta \mathbf{A I C}$ \\
\hline Model 1 & $\begin{array}{c}\text { Estimate (SE) } \\
\mathrm{p}\end{array}$ & $\begin{array}{c}0.53(0.75) \\
0.48\end{array}$ & $\begin{array}{c}-0.72(1.92) \\
0.71\end{array}$ & $\begin{array}{c}0.19(0.18) \\
0.30\end{array}$ & $\begin{array}{c}0.02(0.04) \\
0.60\end{array}$ & $\begin{array}{c}0.16(0.44) \\
0.71\end{array}$ & $318 \underline{5}$ \\
\hline Model 2 & $\begin{array}{c}\text { Estimate (SE) } \\
p\end{array}$ & $\begin{array}{c}0.41(0.69) \\
0.55\end{array}$ & $\begin{array}{c}-0.004(0.15) \\
0.98\end{array}$ & $\begin{array}{c}0.22(0.17) \\
0.19\end{array}$ & $\begin{array}{c}0.02(0.04) \\
0.57\end{array}$ & - & $317 \underline{4}$ \\
\hline Model 3 & $\begin{array}{c}\text { Estimate (SE) } \\
\mathrm{p}\end{array}$ & $\begin{array}{c}0.41(0.63) \\
0.51\end{array}$ & $\begin{array}{l}- \\
-\end{array}$ & $\begin{array}{c}0.22(0.15) \\
0.15\end{array}$ & $\begin{array}{c}0.02(0.04) \\
0.57\end{array}$ & $\begin{array}{l}- \\
-\end{array}$ & $315 \underline{2}$ \\
\hline Model 4 & $\begin{array}{c}\text { Estimate (SE) } \\
\mathrm{p}\end{array}$ & $\begin{array}{c}0.48(0.62) \\
0.44\end{array}$ & $\begin{array}{l}- \\
-\end{array}$ & $\begin{array}{c}0.22(0.15) \\
0.15\end{array}$ & $\begin{array}{l}- \\
-\end{array}$ & - & $313 \underline{0}$ \\
\hline
\end{tabular}

